\title{
A Random Forest ML Approach to Mapping the Sedimentary Stratigraphy and Prospecting for Stratiform Copper Deposits using Soil Geochemistry in the Munster Basin, Southwestern Ireland \\ TOM F WESBY
}

First Quantum Minerals Ltd

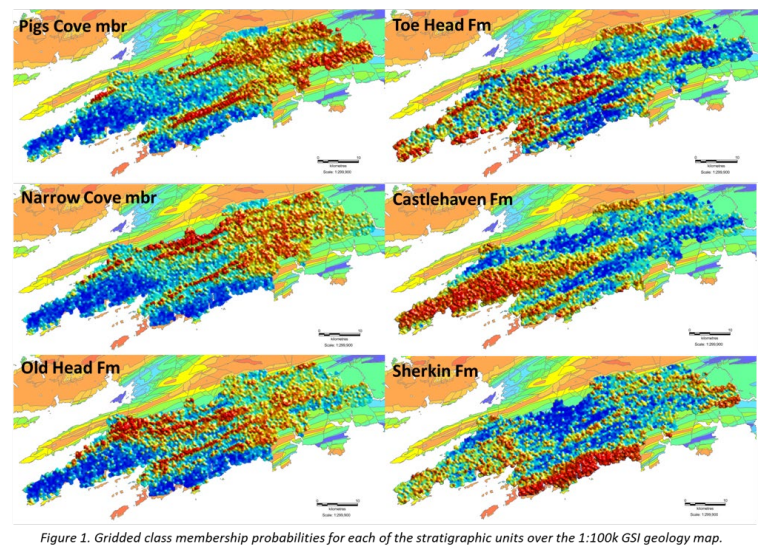

Presenting Author: tom.wesby@fqml.com

The regolith of Southwestern Ireland is composed of transported periglacial deposits and a mixture of peaty and brown podzols that developed in situ over weathered bedrock. Outcrops of bedrock form a modest fraction of the area and decrease inland from coastal areas that are exposed to more rapid erosion from the sea. Reconnaissance fieldwork to prospect for base metals had identified two stratigraphic formations of the Devonian-Carboniferous Munster Basin as viable targets for stratiform copper deposits. Our aim was to map out the position of the prospective formations in areas with limited outcrops. However, the mineral exploration industry perceives complex regoliths as an exploration risk when assessing the prospectivity of new areas due to the difficulty in resolving the concentrations of target and pathfinder metals between the different regolith types.

In this case study we used a conventional random forest approach with minimal supervision in order to classify a grid of $>4,000$ soil samples collected by hand augur over an area of $1,100 \mathrm{sqkm}$. All samples were collected and logged during the summer of 2017. Magnetic susceptibility was measured using a handheld meter and 60 element assays were provided by ALS Loughrea using a full digest method. In addition, an SRTM digital elevation map of the area was downsampled to match the sampling locations. The key predictive dataset used to map the sedimentary stratigraphy was a $1: 100 \mathrm{k}$ scale geological map from the Geological Survey of Ireland. Class membership probabilities, entropy, and accuracy of the random forest classification were calculated using the open-source toolkit Orange.

The resulting stratigraphic point map is largely consistent with the mapped geology (classification accuracy varied from 92 $43 \%$ ) and shows that the sedimentary bedrock can be mapped through most but not all local regolith types. The highest ranking variables included both major and trace elements, the SRTM elevation, and magnetic susceptibility. The most value to the exploration industry is identifying areas where the classified soil geochemistry suggests changes to the stratigraphic map, thereby identifying new prospects and providing important context to areas with little outcrop. Pre-competitive datasets collected by government agencies can be analysed similarly. 